\title{
COMO DEVEM SER
}

\section{AS POLITICAS DE \\ DESENVOLVIMENTOE \\ COOPERACÁto \\ INTERNACIONAL NA}

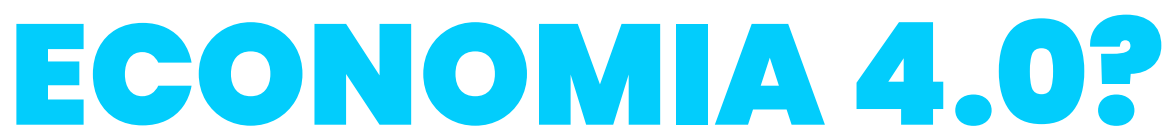

Marcos Troyjo

Uma das principais características da economia contemporânea reside no pressuposto de que a robótica e a automação, bem como outras tecnologias de ponta, ameaçam a existência de profissões e postos de trabalho como os conhecemos até agora.

A hipótese é, em certa medida, verdadeira. "Desenhista remoto em 3D", "administrador de dados em nuvem", "curador de inteligência artificial (IA) aplicada à logística" são algumas das novas profissões. Elas fazem com que algumas ocupações - gestão de imagem em rede social ou web designer -, que a pouco tempo atrás eram novidades, já não pareçam tão inovadoras.

- poder de trensformeģão de teenelogie sobre o mundode trabalhoé imenso. Assim, é um erro ereditur à globalizeçễo - pepel de pringipel eulpade pelc obsoleseêneid de regi̋es e setores tradieionelmente manufatureiros.

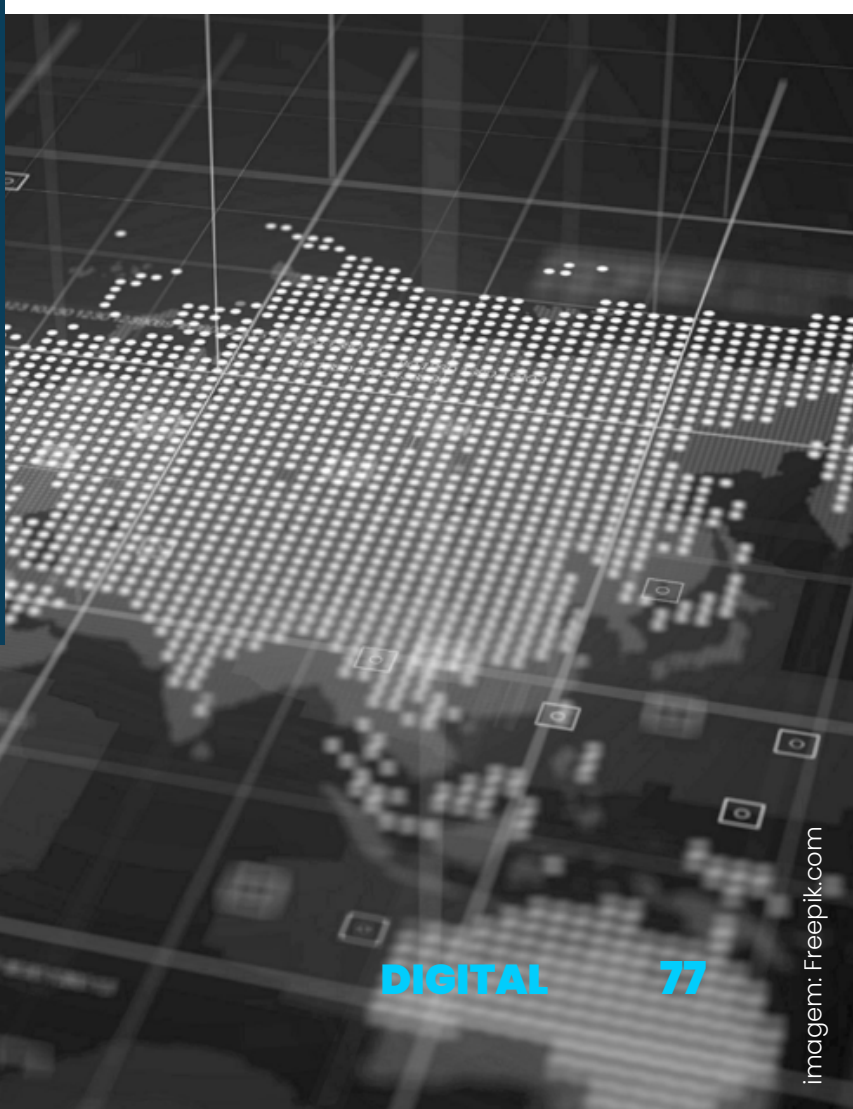


A inovação se dá por processos de destruição criativa. Isso significa, necessariamente, uma espécie de dinâmica "evolucionária". Portanto, o papel da tecnologia tem um peso relativo potencialmente tão grande quanto o da expansão das redes globais de valor.

Quando determinadas atividades industriais se transferem a outros países, seja por razão de maior produtividade, especialidade ou menor custo, os ganhos de eficiência podem, eventualmente, ser utilizados no reinvestimento em áreas de maior valor agregado (como marketing, design ou pesquisa e desenvolvimento).

Ao observarmos esses fenômenos, estamos diante da fundamental transição da "manufatura" para a 'mentefatura" (em inglês, diríamos "from manufacturing to mindfacturing"). Embora o conceito de "mentefatura" seja novo, o fenômeno que ele descreve é perceptível em diferentes graus em variados momentos históricos. Ao longo do século XIX, metrópoles como Londres ou Paris apresentavam grande fatia de sua atividade econômica concentrada no setor industrial. Ao longo do tempo, se tornaram praças de serviço e entretenimento.

Na mesma medida, a transição entre diferentes "eras" tecnológicas também impacta a natureza do trabalho. As tecnologias de natureza analógica estão sendo substituídas pelas de caráter digital, mas este não é o fim da viagem. Assistimos à ascensão de ferramentas cognitivas e com ela interagimos. Tecnologias como a inteligência artificial (a propósito, talvez o termo "inteligência aumentada" seja mais adequado) estão aqui para ficar.

Pesquisas recentes em economias avançadas registram que muitos temem mais pelo impacto de tecnologias como a IA sobre seus empregos do que aquele causado pela imigração ou pela mudança de elos da cadeia produtiva a outros países. Tais pesquisas também apontam que a maioria dos profissionais em economias mais maduras entendem que as novas tecnologias mais atuam na destruição do que na criação de oportunidades de trabalho.

A propósito, a relação imigrantes-tecnologia-emprego, no mais das vezes, parece percorrer o caminho inverso. Com o estabelecimento de restrições à imigração, mudam-se os fluxos de investimento de empresas estrangeiras intensivas em tecnologia.

Alguns países, como o Canadá, apresentam menos restrições à imigração de pessoal qualificado em setores de alta tecnologia. Em consequência, muitos têm posição de destaque na corrida global por talento e atraem grande volume de start-ups tecnológicas.

Como vimos, a preocupação com o efeito da introdução de novas tecnologias sobre o trabalho não é nova. No começo do século XIX, com a Revolução Industrial a pleno vapor, arregimentou-se o Ludismo - um movimento na Inglaterra em que artesãos invadiam fábricas de tecelagem e destruíam as máquinas que aparentemente Ihes estavam roubando o ganha-pão. 
Embora alguns historiadores argumentem que o movimento em si nada tinha contra as máquinas, mas tudo em favor de melhores condições de trabalho, o Ludismo ficou marcado como esforço estéril perante a imperiosa dinâmica de inovação.

O quão esse debate sobre tecnologia e trabalho é envolto em sutilezas analíticas pode ser esclarecido com o exame contemporâneo de economias como as de EUA, China, Japão e Alemanha. Trata-se aqui, respectivamente, dos países que detêm os quatro maiores PIBs (produto interno bruto) do mundo. São, da mesma forma, as quatro nações que mais depositam patentes, uma boa medida do ritmo e volume de inovação, na WIPO (Organização Mundial da Propriedade Intelectual).

9

.

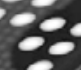

$200-20$

2000030

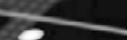

2

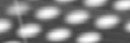
20 2 7

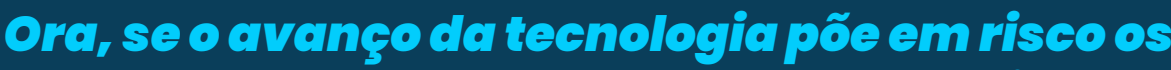
pestos de trabalho, e esse processe obvicmente é algo que não eomeçou agord, erd de supor que o desemprego relceionado à teenologic erescesse progressiva e estruturalmente nesses economics. No entento, no contexto pré-covID-19, - desemprego nessas economics encontrave-se em patemar eboix dos $4 \%$.

\section{-}
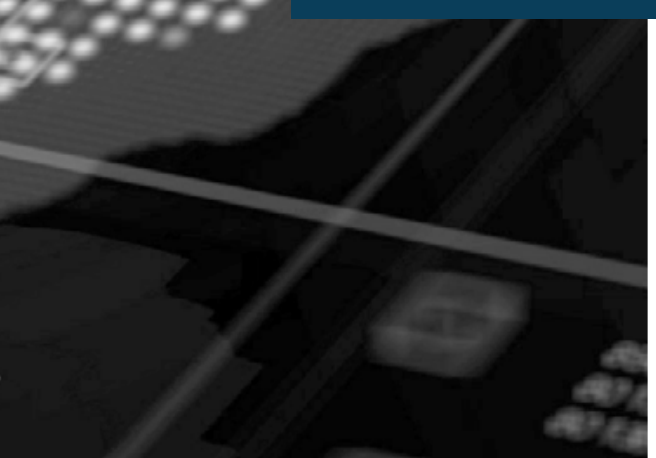

Além de seu elevado índice de inovação tecnológica, esses países apresentam em comum a grande escala comparativa de suas economias; o perfil, no agregado, como as quatro maiores nações comerciantes (medido pelo fluxo nominal combinado de exportações e importações); boa governança macroeconômica; e instituições que incentivam e asseguram a inovação.

Em síntese, economias mais competitivas são aquelas que permitem a transformação do mundo do trabalho e da empresa. Em vez de os evitar, preparamse para o desafio de novos tempos. Reformas modernizantes internas, acordos internacionais de comércio e investimento, e investimentos nos aspectos educacionais da força de trabalho são, no limite, os responsáveis pela combinação alta competitividadedesemprego baixo. 
Nesse contexto, de modo a evitar grandes assimetrias internacionais, o papel da cooperação é fundamental. Assim, a própria ideia de "plano econômico", que dominou o imaginário dos economistas no século $X X$, passa por uma ressignificação. Seu conceito original, na contramão do que pregavam os liberais clássicos, representava intervenção clara do governo no curso espontâneo dos mercados.

Daí um plano ser (teoricamente) sempre a tentativa de acelerar um processo ou corrigir um rumo equivocado. É um "atalho" para determinado objetivo. A opção por "planos" marca a conhecida divisão entre pensamento ortodoxo e heterodoxo em política econômica, mas isso não precisa ser necessariamente assim.

Nos últimos 70 anos, uma das mais exitosas estratégias dessa natureza, aplicada logo após a Segunda Guerra, foi o Plano Marshall. Ajudou a transformar países derrotados no grande conflito em economias competitivas e prósperas.

Hoje, o fenômeno com maior potencial de estabelecer pontes cooperativas internacionais ou, ao contrário, alargar ainda mais o fosso de desenvolvimento entre os países, é a chamada "Economia 4.0". Talvez esse termo, mais ainda do que a designação "Quarta Revolução Industrial", seja mais apropriado para descrever o ecossistema de conhecimento, tecnologia e empreendedorismo em que estamos ingressando.

Se não mais o capital, mas o talento, é o fator determinante do êxito nesta "Nova Era de Adaptação", em que medida faz sentido falar da necessidade de um "Plano Marshall tecnológico"?

A grande distêneị mundịa não é mais dpenas os que têm e es que não têm. Está entre os "eonectades" e "não conectados". A fusc̃o talento-teenologị permite a países "adeptaçöes serialis". E, a partir

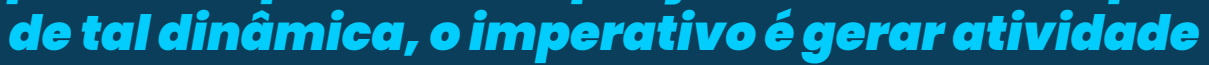
produtiva que vá além das tradieionalis vantagens eomparativas rieardienas.

Uma nova onda de cooperação internacional para o florescimento da Economia 4.0 estaria repleta de desafios. Por exemplo: quais são as implicações do termo "infraestrutura" para a Economia 4.0? Qual o sentido contemporâneo de um novo Plano Marshall que viesse a fornecer infraestrutura de tecnologias da informação para o mundo em desenvolvimento? 
Infraestrutura convencional na economia industrial foi classicamente representada pela malha logística - por portos, aeroportos, ferrovias, estradas, etc. Até a infraestrutura tradicional tem de ser intensiva em tecnologia. Talvez aí resida o mais preciso significado da expressão "smart infrastructure". Daí, infraestrutura compreende modalidades velozes e seguras de conectividade. Igualmente, consiste na relação ágil entre universidades, unidades de pesquisa e desenvolvimento e sua tradução em produtos para o mercado.

Nesse eontextor repenserr polfitiecs de desenvolvimento tornd-se ainde mais eomplexo. A velocidade com que aeroportos ou estradas se torncm obseletos é dramaticermente inferior à repidez com que e fio de eobre foi superado pelc fibra ótice. Ou esta pela progressiva utilizeçço de tecnologias de sctétilies.

Um bom exemplo dessa "obsolescência prematura", que crescentemente marcará a Economia 4.0, é a velocidade com que os computadores do tipo desktop foram superados pela ascensão de tablets e smartphones.

Eis um grande dilema para um "Plano Marshall tecnológico" contemporâneo: além de exigir um nível de cooperação internacional com grande harmonia, corre-se o risco de apostar em determinadas tecnologias incapazes de encurtar a distância entre economias baseadas no conhecimento e aquelas às voltas ainda com a primeira revolução industrial.

É por isso que deveríamos entender por "Plano Marshall tecnológico" não um programa específico, mas um renovado chamamento à cooperação internacional, a mostrar que o combate ao "gap" digital fará com que, no limite, todos os países podem sair ganhando. 
